ZOOLOGIA 32 (6): 532-537, December 2015

http://dx.doi.org/10.1590/S1984-46702015000600011

\title{
Susanlimae ianwhittingtoni gen. nov., sp. nov. (Monogenoidea: Dactylogyridae), a dweller of the gill rakers of Pseudeutropius moolenburghae (Siluriformes: Schilbeidae) from Sumatra
}

\author{
Walter A. Boeger ${ }^{1,{ }^{*}}$, Antoine Pariselle ${ }^{2} \&$ Luciana Patella ${ }^{1}$
}

\author{
'Laboratório de Ecologia Molecular e Parasitologia Evolutiva, Departamento de Zoologia, Universidade Federal do Paraná. \\ Caixa Postal 19073, 81531-980 Curitiba, Paraná, Brazil. \\ 2 Institut des Sciences de l'Évolution, IRD, BP 1857, Yaoundé, Cameroon \\ *Corresponding author. Email: wboeger@gmail.com
}

\begin{abstract}
A new genus and species of Monogenoidea, Susanlimae ianwhittingtoni gen. nov., sp. nov., are proposed for dactylogyrids collected from the "Nuayang tipis", Pseudeutropius moolenburghae Weber \& de Beaufort, 1913, which inhabits freshwater in Sumatra. While clearly a member of a putative clade that includes Asian and African catfish parasites, S. ianwhittingtoni sp. nov. differs from most members of this clade by having a bifurcated haptor that embraces the gill rakers of its host. This haptoral morphology and mode of attachment also occur in species of Bifurcohaptor Jain, 1958. However, species of Susanlimae gen. nov. are easily distinguished by the comparative morphology of their haptoral armature. In Susanlimae gen. nov., the ventral and dorsal bars are single, elongated, and inverted u-shaped (ventral bar short and two short dorsal bars in Bifurcohaptor spp.); the dorsal anchor is robust with well-defined roots (reduced roots and elongate shaft in Bifurcohaptor spp.); and the ventral anchor has an elongated, deep root (inconspicuous in Bifurcohaptor spp.).
\end{abstract}

KEY WORDS. Catfish; Dactylogyridea; ectoparasite; Platyhelminthes; Polyonchoinea.

During a survey of monogenoidean parasites from the freshwaters of Sumatra (Indonesia), specimens of a new genus and species were collected from"Nuayang tipis", Pseudeutropius moolenburghae Weber \& de Beaufort, 1913. This fish is a demersal species inhabiting rivers and lakes in Sumatra and Borneo (Froese \& Pauly 2015). The new species is unique among the Dactylogyridae in having haptoral structures adapted to embrace the gill rakers of the host. The organization and morphology of the hard structures within the haptor warrant the proposal of a new genus to accommodate the new species. A similar attachment style, however, occurs in species assigned to other monogenoid genera and families.

\section{MATERIAL AND METHODS}

Host fish used in this research were captured by local fishermen in May 2005 from the Batang Hari River near the village of Kubu Kandang, Sous-district Pemayung, Province of Jambi, Sumatra, Indonesia. They were acquired from the local fish market and were immediately preserved in ethanol (70$80 \%$ ) for subsequent processing.
In the laboratory, the gills of each fish were removed and their parasites were collected from the sediment with the aid of probes and forceps under a dissecting scope. Some specimens were stained with Gomori's trichrome and mounted in Damar's gum for study of their soft anatomy; other specimens were cleared and mounted in Hoyer's mounting medium (prepared as in HUMASON 1979) for study of their hard structures. Illustrations were prepared using a camera lucida on an Olympus BX51 microscope equipped with phase contrast. Measurements, all in micrometers, were taken following the procedures of Mizelle \& Klucka (1953). In the descriptions, the mean is followed by the range and the number of structures measured (n), in parentheses; the length of the body includes the haptor (longitudinal axis of haptor). The length of the male copulatory organ (MCO) and bars represent their actual length measured with the software ImageJ (SCHNeIder et al. 2012). The hooks are numbered according to MizelLe (1936). The type specimens are deposited in the parasitological collections of the Instituto Oswaldo Cruz (Rio de Janeiro, Brazil) (CHIOC) and the Muséum national d'Histoire naturelle (Paris, France) (MNHN). 


\section{TAXONOMY}

\section{Class Monogenoidea Bychowsky, 1937 Subclass Polyonchoinea Bychowsky, 1937 Dactylogyroidea Bychowsky, 1937 Dactylogyridae Bychowsky, 1933 Susanlimae gen. nov.}

Diagnosis. Body fusiform, strongly flattened dorsoventrally, comprising body proper (cephalic region, trunk) and haptor; peduncle inconspicuous. Tegument smooth. Cephalic lobes inconspicuous; cephalic glands unicellular, lateral or posterolateral to pharynx. Eyespots 4; granules small, ovate. Mouth subterminal, midventral, prepharyngeal; pharynx muscular, glandular; oesophagus short or inconspicuous; intestinal caeca two, non-confluent, lacking diverticula. Common genital pore midventral at level of intestinal bifurcation. Gonads intercaecal, tandem, germanrium posterior to testis. Vas deferens looping left intestinal caecum; seminal vesicle a simple dilation of vas deferens. Copulatory complex comprising MCO, lacking accessory piece. MCO sclerotized, tubular. Seminal receptacle pregermarial; vaginal pore single, ventral, intercaecal, non-sclerotized; vaginal duct intercaecal, non-sclerotized. Vitellaria in trunk, absent from regions of other reproductive organs. Haptor bifurcated, composed by bilateral "arms"; with dorsal, ventral anchor/bar complexes, seven pairs of similar hooks (5 pairs ventral, 2 pairs dorsal). Hook with shank comprising single subunit. Bars elongate, inverted U-shaped. Ventral anchor with elongate deep root. Superficial root of dorsal anchor provided with accessory sclerite (= cuneus). Parasites of the gill rakers of species of Siluriformes (Actinopterygii).

Type species. Susanlimae ianwhittingtoni sp. nov.

Etymology. The generic epithet is in honor of Dr. Lee Hong Susan Lim (1952-2014) (University of Malaya in Kuala Lumpur), a Malaysian parasitologist and a good friend of the first two authors. Dr. Lim is greatly responsible for most of our knowledge of the diversity of Monogenoidea from Asian Siluriformes.

\section{Susanlimae ianwhittingtoni gen. nov., sp. nov.} Figs. 1-9

Description (based on 6 specimens -3 stained, 3 cleared). Body $330(227-394, \mathrm{n}=3)$ long; greatest width $92(82-99, \mathrm{n}=3)$ at level of gonads. Eyespots 4 , accessory granules scarce in cephalic region. Pharynx ovate, $38(35-44, \mathrm{n}=3)$ long, 28 (26$29, \mathrm{n}=3)$ wide. Testis ovate, often transverse, $25(13-39, \mathrm{n}=3)$ long, 49 (39-57, $\mathrm{n}=3)$ wide; vas deferens looping left intestinal caecum; seminal vesicle elongate; prostatic reservoir not observed. MCO 61 (53-77, n = 3) long, wide, curved on itself; base of MCO wide. Germarium ovate, $42(23-57, \mathrm{n}=3)$ long, $32(27-39, n=3)$ wide. Uterus not observed. Vaginal pore single, ventral, at midlength of the body. Vitellaria dense, overlapping caeca. Hooks similar in shape, with slightly erected thumb, straight shaft, short point; hooks $16(15-19, \mathrm{n}=6)$ long; shank proximally bulbous; 5 ventral pairs, one dorsal pair (hook pair 6) located at the distal extremity of the haptoral arms; one dorsal hook (hook pair 7) located at midlength of each bilateral arm. Ventral anchor $86(73-94, ; \mathrm{n}=3)$ long, base $10(8-11$, $\mathrm{n}=3$ ) wide, delicate, with well differentiated roots, deep root about 10 times longer than superficial root, straight shaft, point recurved, about $1 \frac{1}{2}$ shaft length. Dorsal anchor 73 (60-82, $\mathrm{n}=$ 3) long, base $51(42-61, \mathrm{n}=3)$ wide, robust base, with short deep root, robust superficial root with small cuneus, shaft and point evenly curved, shaft with small external indentation near midlength. Ventral bar 389 (279-492, n = 3), delicate, tapering towards extremities, medially hinged. Dorsal bar 250 (192-303, $\mathrm{n}=3$ ) long, robust, with slightly tapering ends. Eggs not observed.

Type host. Pseudeutropius moolenburghae Weber \& de Beaufort, 1913 (Siluriformes: Schilbeidae)

Site of infection. Gill rakers.

Type locality. Batang Hari river, near the Village de Kubu Kandang, Sous-district Pemayung, Province Jambi, Indonesia. Latitude: $1^{\circ} 36^{\prime} 17.51^{\prime \prime}$, Longitude: 103¹9'16.65"E. Date: May 2005. Specimens deposited. CHIOC 38202 a (holotype); 5 paratypes CHIOC 38202 b,c, MNHN HEL545, HEL546. One paratype kept in the private collection of AP.

Etymology. The specific epithet is proposed in honor of the late Dr. Ian Whittington (1960-2014), South Australian Museum and University of Adelaide, Australia. Dr. Whittington passed away too soon, but not before making an impressive contribution to the biology, taxonomy, and phylogeny of Monogenoidea, especially those of Capsalidae.

\section{DISCUSSION}

Despite its apparently unique morphology, S. ianwhittingtoni shares many features with other dactylogyrid parasites of siluriform fishes from Asia and Africa. For instance, the ventral anchors are significantly smaller than the dorsal anchors, each dorsal anchor has an accessory sclerite (= cuneus) associated with its superficial root, and the ventral bar tends to be Vshaped or composed of two smaller bars, articulated or not. These features are common in species of several genera, such as Thaparocleidus Jain, 1952, Cornudiscoides Kulkarni, 1969 (Fig. 10), Bifurcohaptor Jain, 1958 (Fig. 11), Mizelleus Jain, 1957, Bychowskyella Achmerow, 1952, Quadriacanthus Paperna, 1961, Malayanodiscoides Lim \& Furtado, 1986, Notopterodiscoides Lim \& Furtado, 1986, Pseudancylodiscoides Yamaguti, 1963, and Paraquadriacanthus Ergens, 1988. Together with other characteristics, they may represent synapomorphies providing support for the shared ancestry of these genera. Lim et al. (2001) for example, regarded the dactylogyrids mentioned above, together with other species lacking the aforementioned combination of characters, as members of Ancylodiscoidinae Gussev, 1961. In this study, however, we accept the hypotheses of KRITSKY 


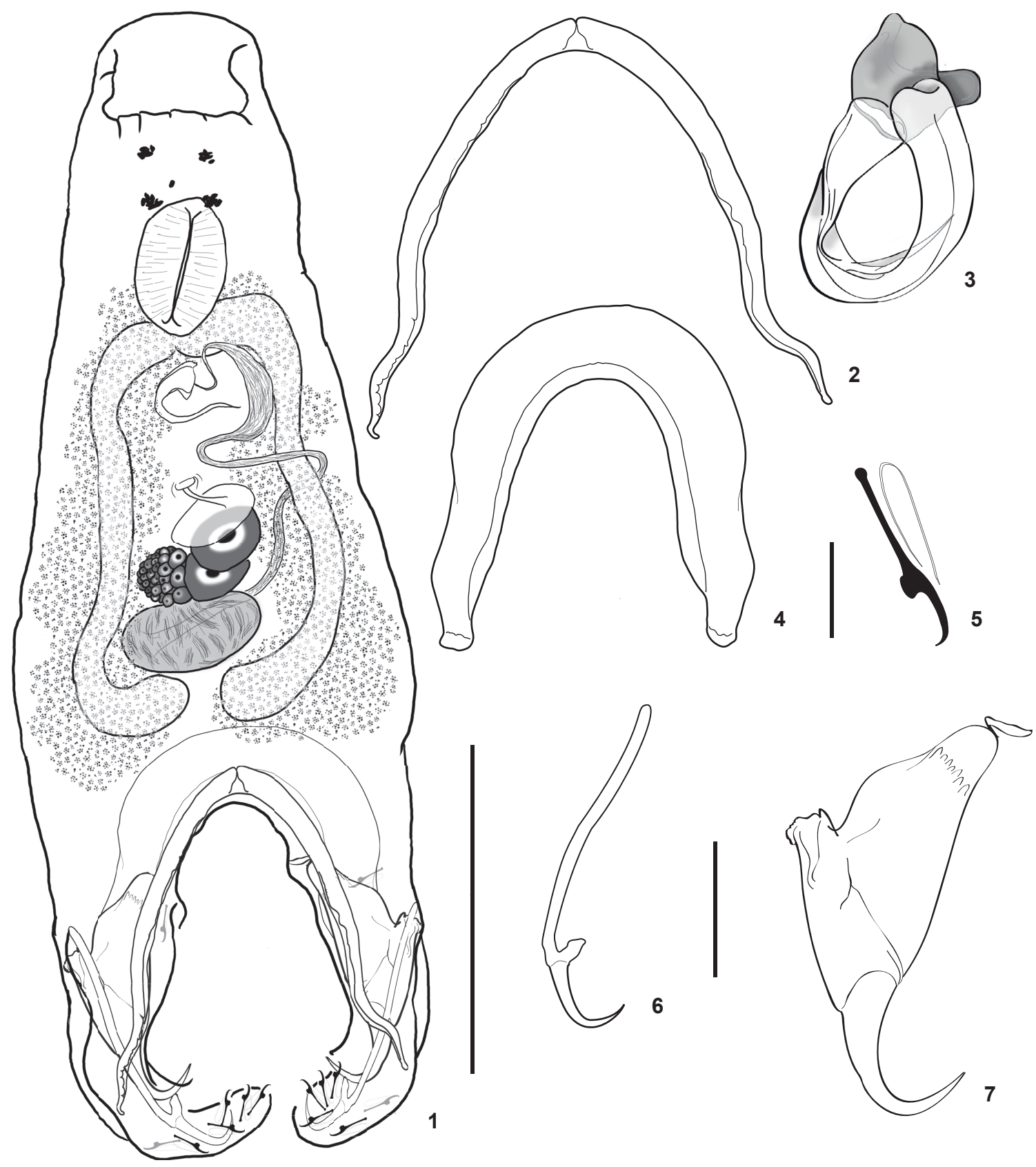

Figures 1-7. Susanlimae ianwhittingtoni sp. nov.: (1) holotype, ventral view; (2) male copulatory complex; (3) ventral bar; (4) dorsal bar; (5) hook; (6) ventral anchor; (7) dorsal anchor. Scale bars: $1=100$ ìm, $2=25$ ìm, 3, 4, 6, 7 = 50 ìm, 5 = 5 ìm.

\& Boeger (1989) and ŠimkovÁ et al. (2003) and refrain from recognizing Ancylodiscoidinae (as well as Ancyrocephalinae) as valid, since this group is not monophyletic according to published phylogenies.

Unlike most species of Monogenoidea of catfishes, $S$. ianwhittingtoni attaches to its host by embracing the gill rakers and penetrating the epithelium with anchors and hooks located at the distal extremities of the bifurcated haptor (haptoral arms) (Figs. 8, 9). A similar kind of attachment is found in species of Bifurcohaptor, but in the latter the attachment is to the gill filament rather than the gill rakers (KeARN \& BIJUkUMAR 1997). Bifurcohaptor indicus Jain, 1958 (and likely all other spe- 


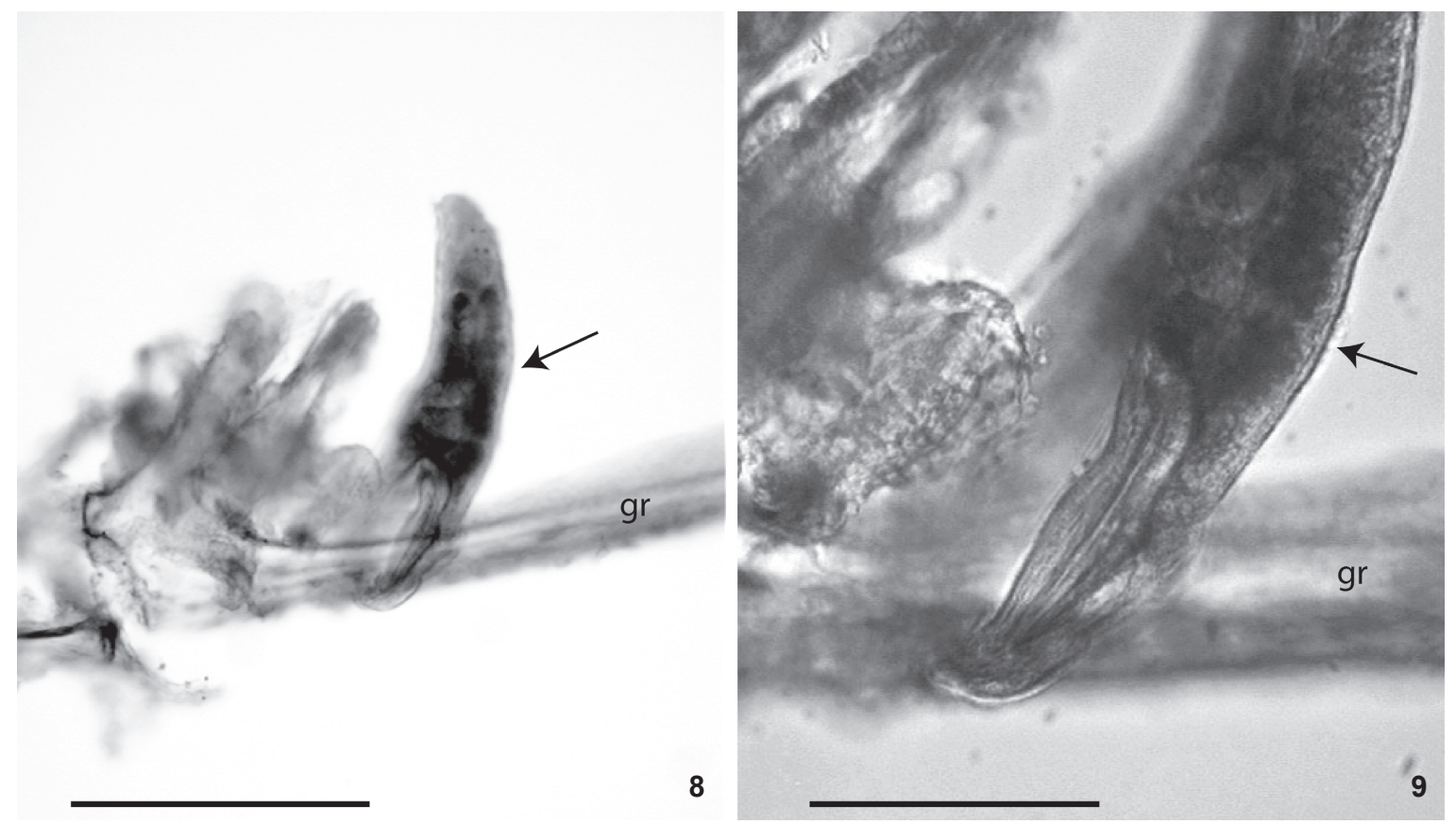

Figures 8-9. Photomicrographs of specimens of Susanlimae ianwhittingtoni sp. nov. (arrows) attached to the on the gill rakers (gr) of Pseudeutropius moolenburghae. Scale bars: $8=250$ ìm, $9=100 \mathrm{im}$.

cies of this genus) embraces only part of the gill filament, the afferent border (see KeARN \& BIJUKUMAR (1997). However, comparative analysis of the hard parts involved in the attachment in S. ianwhittingtoni and B. indicus indicates that this mode of attachment likely originated from independent evolutionary events (see Figs. 11, 12). In the new species, both ventral and dorsal bars are inverted $\mathrm{V}$ or U-shaped, the ventral anchor depicts an unusually long deep root, while the dorsal anchor is robust with conspicuous roots. In species of Bifurcohaptor, the dorsal bar is small and robust; the ventral bar is split into two separate parts, each positioned by each ventral anchor and located distally in the haptoral arms; and the dorsal anchor is greatly elongated, almost as long as each respective haptoral arm, lacking conspicuous roots.

Even though haptors adapted to embrace the gill filaments or gill rakers are unusual among the Monogenoidea, species of other genera of Polyonchoinea have similar functional morphology, including those of Dactylogyridae and Diplectanidae. The single species of Furcohaptor, F. cynoglossi Bijukumar \& Kearn, 1996 (Fig. 13), parasite of the gill filaments of the flatfishes Cynoglossus macrostomus Norman, 1928 and Cynoglossus puncticeps (Richardson, 1846), has haptoral arms but the haptoral armature is reduced. The genus was originally assigned to the Ancyrocephalinae, but is most likely a member of Diplectanidae. This hypothesis is supported by the morphology of the anchor and divided bar, greatly resembling those of Diplectanidae; by the presence of a male copulatory organ directed posteriorly; and the morphology of the head area and head organs. A definitive transfer of Furcohaptor to Diplectanidae may not happen until analysis of molecular data and description of the internal organs (not provided in the original description of the species) (BIJUKUMAR \& KeARn 1996). In F. cynoglossi, the haptoral arms are elongate and the hard structures (hooks, bars, and anchors) are located solely at the distal portion of these arms.

Another diplectanid, Aetheolabes goldiensis Boeger \& Kritsky, 2009 (Fig. 14), a parasite of the freshwater Sciaenidae Plagioscion sp. (and its likely congeneric Diplectanum umbrinum Tripathi, 1959 - see BoEger \& Kritsky 2009) also presents an embracing haptor. In species of Aetholebes Boeger \& Kritsky, 2009 the ventral bar is short, robust, and located at the base of the haptoral arms; the dorsal bars are long, almost as long as the haptoral arms, and articulate proximally; and the anchors are located distally within the arms. As Susanlimae gen. nov. and Aetholebes are members of distinct families within the Polyonchoinea, the general similarities in haptor morphology are simply the result of convergent evolution.

\section{ACKNOWLEDGMENTS}

Fish specimens were donated for parasite inspection by the "Catfish Asia Project" (supported by the European Commission) of L. Pouyaud and J. Slembrouck. WAB is a research fellow of the Conselho Nacional de Desenvolvimento Científico e Tecnológico, Brazil. This is publication ISE-M 2015-226 SUD. 


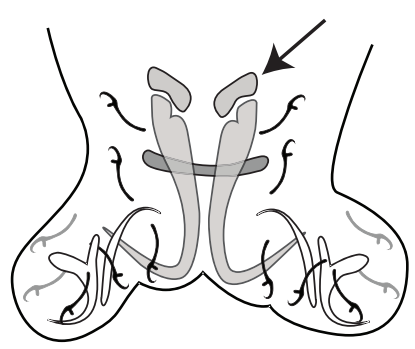

10
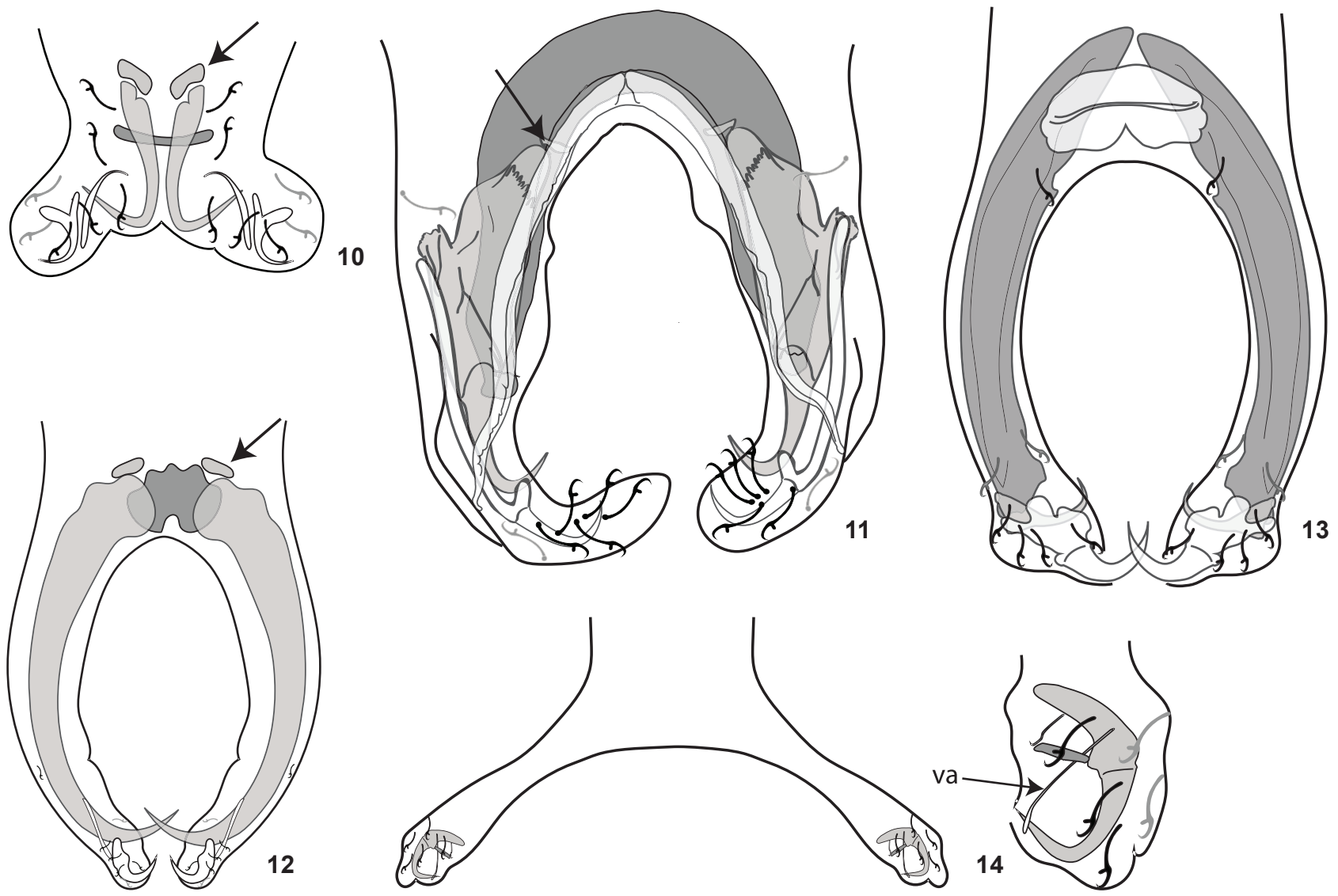

Figures 10-14. Morphology and organization of the haptoral armature of different groups of Dactylogyrinea: (10) haptoral armature of Cornudiscoides bagri Lim, 1987 modified from LIM (1987); (11) haptoral armature of Susanlimae ianwhittingtoni sp. nov.; (12) haptoral armature of Bifurcohaptor modified from KEARN \& BIJUKUMAR (1997); (13) haptoral armature of Furcohaptor cynoglossi modified from BiJukUMAR \& KeARN (1996); (14) haptoral armature of Aetheolebes goldiensis modified from BoeGer \& KRITSKy (2009). Ventral sclerites are clear; light gray indicates the dorsal anchor; dark gray indicates dorsal bar; black hooks are ventral; gray hooks are dorsal. Arrows indicate the accessory sclerite; va = reduced ventral anchor. Figures are not to scale. Number and/or distribution of hooks in figures 10 , 12,13 are merely illustrative, as they were not confirmed in type or voucher specimen.

\section{LITERATURE CITED}

Bijukumar A, Kearn GC (1996) Furcohaptor cynoglossi n. g., n. sp., an ancyrocephaline monogenean gill parasite with a bifurcate haptor and a note on its adhesive attitude. Systematic Parasitology 34: 71-76. doi: 10.1007/BF01531213

Boeger WA, Kritsky DC (2009) Neotropical Monogenoidea. 54. Proposal of Aetheolabes n. g. (Dactylogyridae: Diplectanidae), with the description of $A$. goldiensis n. sp. from the gills of 'pescada', Plagioscion sp. (Teleostei: Sciaenidae) in Brazil. Systematic Parasitology 74: 137-142. doi: 10.1007/s11230009-9193-7

Froese, R, Pauly D (2015) FishBase. World Wide Web electronic publication. Available online at: http://www.fishbase.org [Accessed: 04/15/2015]
Humason GL (1979) Animal tissue techniques. San Francisco, W.H. Freeman and Company, 661p.

Kearn GC \& Bijukumar A (1997) The adhesive attitude of the gill-parasitic ancyrocephaline monogenean Bifurcohaptor indicus. International journal for parasitology 27: 607609. doi: 10.1016/S0020-7519(97)00008-8

Kritsky DC, Boeger WA (1989). The phylogenetic status of the Ancyrocephalidae Bychowsky, 1937 (Monogenea: Dactylogyroidea). The Journal of Parasitology 75: 207-211. doi: $10.2307 / 3282767$

Lim LHS (1987) Six new species of Cornudiscoides Kulkarni, 1969 (Monogenea: Ancyrocephalidae) from Mystus species (Bagridae) of peninsular Malaysia. Folia Parasitologica 34: 107-114.

Lim LH, Timofeeva TA, Gibson DI (2001) Dactylogyridean monogeneans of the siluriform fishes of the Old World. 
Systematic Parasitology 50: 159-197. doi: 10.1023/ A:1012237801974

Mizelle JD (1936). New species of trematodes from the gills of Illinois fishes. American Midland Naturalist 17: 785-806. doi: $10.2307 / 2420687$

Mizelle JD, Klucka AR (1953) Studies on monogenetic trematodes. XIV. Dactylogyridae from Wisconsin fishes. American Midland Naturalist 3: 720-733. doi: 10.2307/ 2485203
Schneider CA, Rasband WS, Eliceiri KW (2012) "NIH Image to ImageJ: 25 years of image analysis". Nature Methods 9: 671675. doi: doi:10.1038/nmeth.2089

Šimková A, Plaisance L, Matìusová I, Morand S, Verneau O (2003) Phylogenetic relationships of the Dactylogyridae Bychowsky, 1933 (Monogenea: Dactylogyridea): the need for the systematic revision of the Ancyrocephalinae Bychowsky, 1937. Systematic Parasitology 54: 1-11. doi: 10.1023/ A:1022133608662

Submitted: 17 July 2015

Received in revised form: 11 October 2015

Accepted: 17 October 2015

Editorial responsibility: Marcus V. Domingues

\section{ERRATA}

Page 532:

Where read: The type specimens are deposited in the parasitological collections of the Instituto Oswaldo Cruz (Rio de Janeiro, Brazil) (CHIOC) and the Muséum national d'Histoire naturelle (Paris, France) (MNHN).

Should read: The type specimens are deposited in the parasitological collections of the Instituto Oswaldo Cruz (Rio de Janeiro, Brazil) (CHIOC), the Muséum national d'Histoire naturelle (Paris, France) (MNHN), and the Royal Belgian Institute of Natural Sciences (RBINS).

Page 533:

Where read: Specimens deposited. CHIOC 38202 a (holotype); 5 paratypes CHIOC 38202 b,c, MNHN HEL545, HEL546. One paratype kept in the private collection of AP.

Should be: Specimens deposited. "CHIOC 38202 a (holotype); 6 paratypes CHIOC 38202 b,c, MNHN HEL545, HEL546, RBINS: I.G. 33172/INV.138000." 